\title{
SARD KERNELS FOR CERTAIN BIVARIATE CUBATURES
}

$$
\text { by }
$$

Robert E. Barnhill and David T. Pilcher

\section{Acknowledgments .}

The research of $R$. E. Barnhill was supported by the National Science Foundation with Grant GP 20293 to The University of Utah and by the Science Research Council with Grant B/SR/9652 at Brunei University. The computer calculations and drawings were done on the Univac 1108 at the University of Utah Computer Center with support by The University of Utah Research Committee. 


\title{
SARD KERNELS FOR CERTAIN BIVARIATE CUBATURES
}

\author{
Robert E. Barnhill* and David T. Pilcher*
}

1. Introduction.

Sard's kernel theorems [5] concern the result of applying a bounded linear functional to an appropriate Taylor expansion. The smoothness assumed for the functions determines the Taylor expansion, which in turn determines a norm on the function space. This norm of course defines which linear functionals are bounded.

Stroud [5] has recently used Sard kernels to bound cubature errors for certain cubature rules. In this paper we consider some general properties of the kernels of cross-product cubatures. We also consider some additional cubature rules due to Franke [3] and tc Barnhill and Nielson [1]. Because of the algebraic duality between cross-product cubatures and blending-function cubatures [2], results for either yield results for the other. This duality is stated at the end of Section 3.

\section{Kernels of Cross-Product Cubatures.}

In his Ph.D, thesis, Lether [4] proved various theorems about this type of cubature. In particular, he proved the following theorem: Let $\mathrm{B}_{\mathrm{p}, \mathrm{q}}{ }^{7}[5]$ be the space of functions $\mathrm{f}$ such that the partial derivatives

*Department of Mathematics, The University of Utah, Salt Lake city, Utah 84112. R. E. Barnhill is a Science Research Council Senior Visiting Fellow at Brunel University, Uxbridge, Middlesex, during the 1971-72 academic year. 
$\mathrm{f}_{\mathrm{i}, \mathrm{j}}, 0 \leqq \mathrm{i} \leqq \mathrm{p}, 0 \leqq \mathrm{j} \leqq \mathrm{q}$, exist and are continuous on the rectangle $I=I_{x} \times I_{y}=[a, b] \times[c, d]$ and the point $(\alpha, \beta)$ is in I . Let R and $S$ denote the remainders of quadrature rules with precision $p$ and $q$ on $I_{x}$ and $I_{y}$ with weight functions $u(x)$ and $v(y)$, respectively. If $f$ is in $B r_{p}, q^{7}$, then the remainder of the cross-product rule with univariate remainders $\mathrm{R}$ and $\mathrm{S}$ is the Boolean sum

(1) $\quad(\mathrm{R} \oplus \mathrm{S})(\mathrm{f})=\sum_{\mathrm{j}<\mathrm{q}} \int_{\mathrm{Ix}} \mathrm{f}_{\mathrm{p}, \mathrm{j}}(\mathrm{x}, \beta) \mathrm{K}^{\mathrm{p}, \mathrm{j}}(\mathrm{x}) \mathrm{dx}$

$$
\begin{aligned}
& +\sum_{\mathrm{i}<\mathrm{p}} \int_{\mathrm{I}_{\mathrm{y}}} \mathrm{f}_{\mathrm{i}, \mathrm{q}}(\alpha \alpha y) \mathrm{K}^{\mathrm{i}, \mathrm{q}}(\mathrm{y}) \mathrm{dy} \\
& +\int_{\mathrm{I}} \int \mathrm{f}_{\mathrm{p}, \mathrm{q}}(\mathrm{x} . \mathrm{y}) \mathrm{K}^{\mathrm{p}, \mathrm{q}}(\mathrm{x}, \mathrm{y}) \mathrm{dxdy},
\end{aligned}
$$

where

(2) $\quad \mathrm{k}^{\mathrm{p}, \mathrm{o}}(\widetilde{\mathrm{x}})=-\mathrm{r}\left[\left(\mathrm{x}-(\widetilde{\mathrm{x}})^{(\mathrm{p}-1)} \theta(\widetilde{\mathrm{x}}, \mathrm{x})\right] \int_{\mathrm{I}_{\mathrm{Y}}} \mathrm{v}(\mathrm{y}) \mathrm{dy}\right]$

and

$$
\mathrm{K}^{\mathrm{p}, \mathrm{j}}(\widetilde{\mathrm{x}})=\frac{\mathrm{k}^{\mathrm{p}, 0}(\widetilde{\mathrm{x}})}{\int_{\mathrm{I}_{\mathrm{y}}} \mathrm{V}(\mathrm{y}) \mathrm{dy}} \int_{\mathrm{I}_{\mathrm{y}}} \mathrm{v}(\mathrm{y})(\mathrm{y}-\beta)^{(j)} \mathrm{dy}, \quad \mathrm{i} \leqq \mathrm{j}<\mathrm{p} ;
$$

$\mathrm{k}^{0, \mathrm{q}}(\widetilde{\mathrm{y}})$ and $\mathrm{k}^{\mathrm{i}, \mathrm{q}}(\widetilde{\mathrm{y}}) \mathrm{j}<\mathrm{i}<\mathrm{p}$ are dual to $\mathrm{K}^{\mathrm{p}, 0}(\widetilde{\mathrm{x}}) \quad$ and

$\mathrm{k}^{\mathrm{p}, \mathrm{j}}(\widetilde{\mathrm{x}})$, respectively;

$$
\begin{aligned}
K^{p, q}(\widetilde{x}, \widetilde{y})= & \frac{K^{0, q}\left(\widetilde{y}^{p, 0}(\widetilde{x}, \alpha)\right.}{\int_{I_{x}} u(x) d x}+\frac{k^{p, 0}(\widetilde{x}) G^{0, q}(\widetilde{y}, \beta)}{\int_{I_{y}} u(y) d y} \\
& -\frac{K^{p, 0}(\widetilde{x}) k^{0, q}(\widetilde{y})}{\int_{I_{x}} u(x) d x \int_{I_{y}} v(y) d y},
\end{aligned}
$$




$$
\begin{aligned}
& \text { where } F^{p, 0}(\widetilde{x}, \alpha)=\theta(\widetilde{x}, \alpha) \int_{a}^{b} u(x)(x-\widetilde{x})^{(p-1)} d x \\
& -\int_{a}^{\widetilde{x}} u(x)(x-\widetilde{x})^{(p-1)} d x \text { and } G^{0, q} \text { is dual; }
\end{aligned}
$$

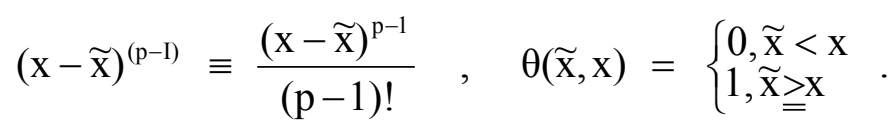

Error bounds for (R X S)(f) can be obtained by the use of Holder's and Minkowski's inequalities. Perhaps the most practical bound utilizes the sup norm on the partial derivatives of $f$. In order to have sharp inequalities, the $\mathrm{L}_{1}$ norm is then used for the Sard kernels. In the cross-product rule case, the expressions (2) for the kernels in (1) have the special property that only three different kernels, $K^{\mathrm{p}, 0}(\widetilde{\mathrm{x}}), \mathrm{k}^{0, \mathrm{q}}(\widetilde{\mathrm{y}})$, and $\mathrm{k}^{\mathrm{p}, \mathrm{q}}(\widetilde{\mathrm{x}}, \widetilde{\mathrm{y}})$, are really involved. For many quadrature rules the norms of the first two have been tabulated by Stroud and Secrest [7]. In general the norms of these two kernels dominate the norm of the third kernel,

\section{Computer Results for Cross-Product Cubatures,}

Let $\mathrm{G}_{2}$ be the two-point Gauss-Legendre quadrature on $[-1,1]$. We consider the cubature $G_{2} X_{2}$ on $[-1,1] X[-1,1]$. The following are contour plots of the two dimensional kernel $\mathrm{K}^{\mathrm{p}, \mathrm{q}}$ for various $\mathrm{p}$ and $\mathrm{q}$ and $(\alpha \beta)$. The shaded regions indicates where the kernel functions are positive. Severe discontinuities occur at the boundaries of these regions. These sketches rule out symmetry properties which might be expected from the definition of the kernels. 


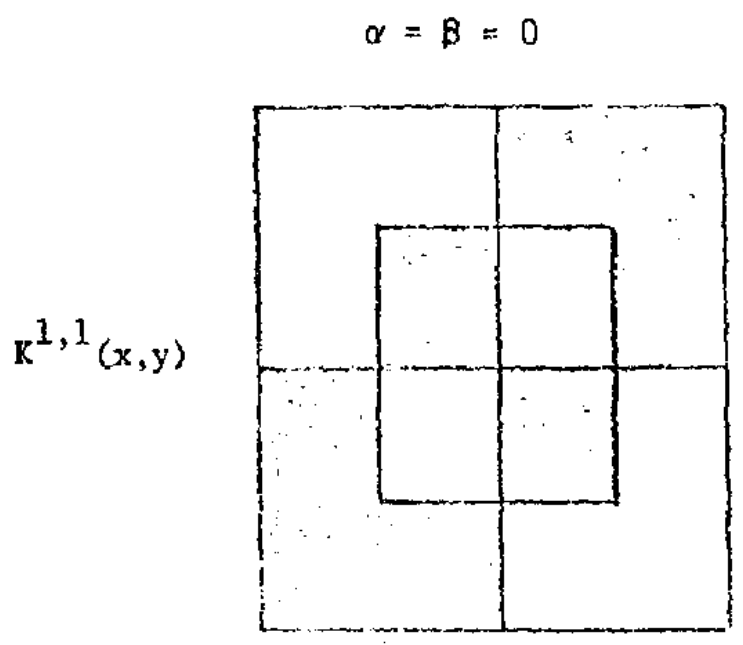

$\alpha=1 \quad \beta=0$
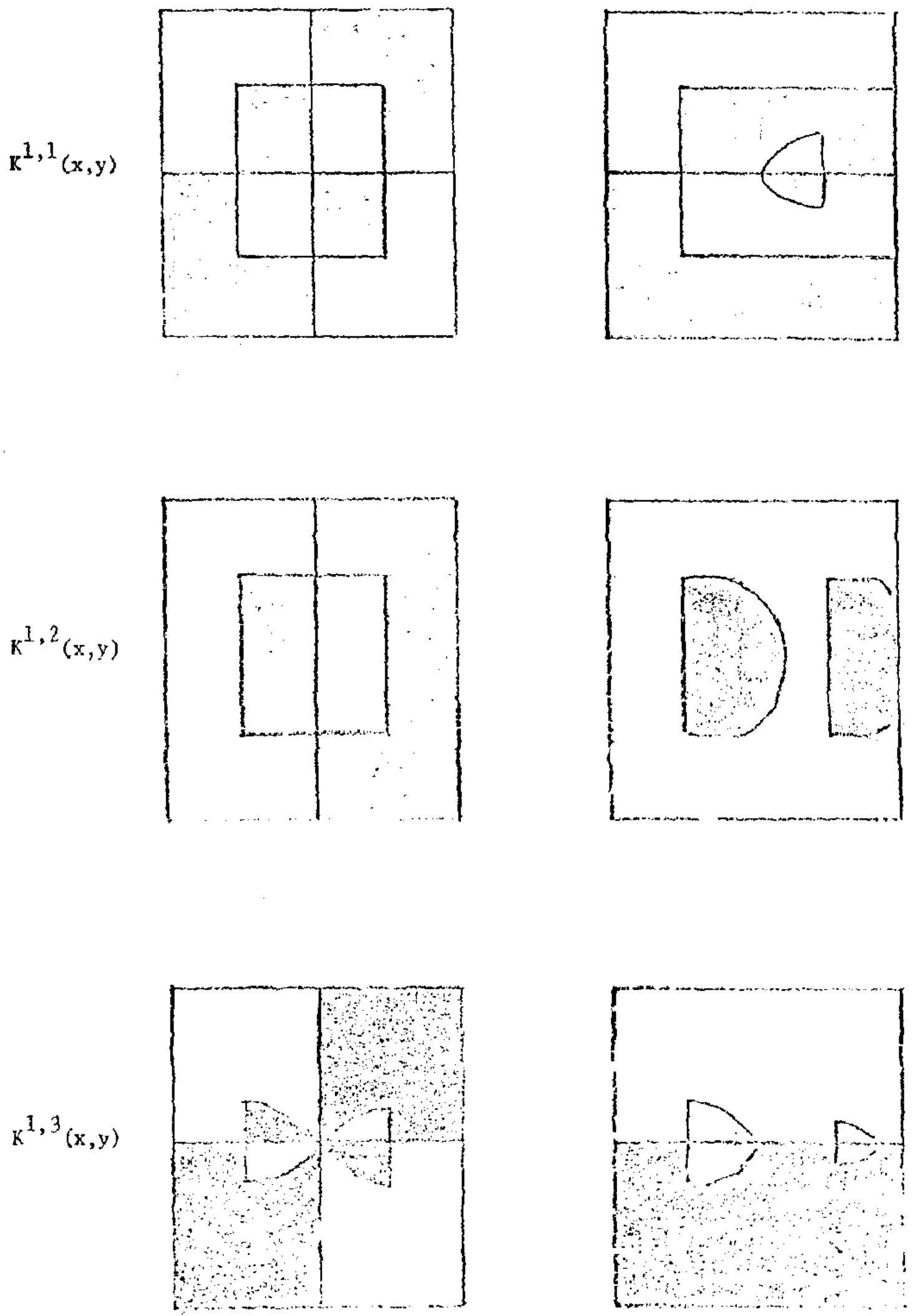
By an isometric view we mean a distance-preserving, threedimensional view drawn by the computer figure 1 is an isometric view of a cabe with edges four inches long.

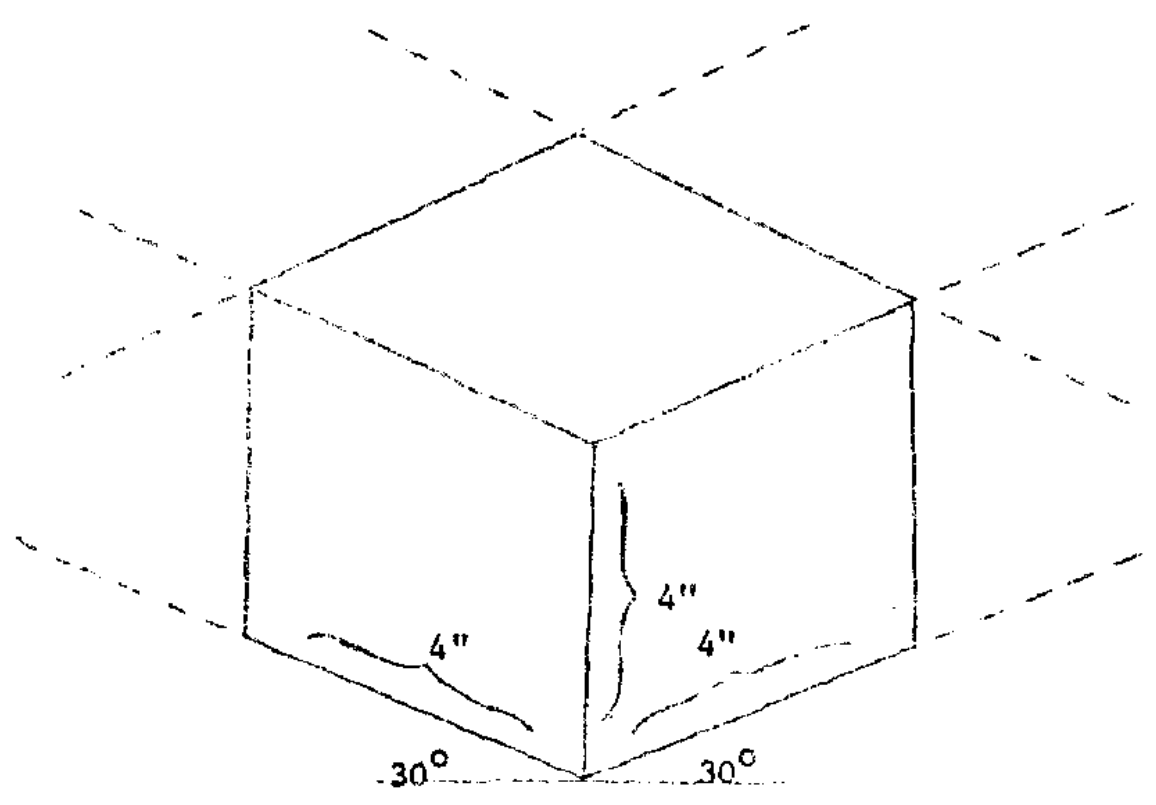

Figure 1. 
Figure 2 is an isometric view of $\mathrm{K}^{1,1}(\mathrm{x}, \mathrm{y})$ for $\mathrm{G}_{1} \times \mathrm{G}_{1}$, where

$\mathrm{G}_{1} \quad$ is the Legendre - Gauss one - point rule with $(\alpha, \beta=(0,0)$. $)$

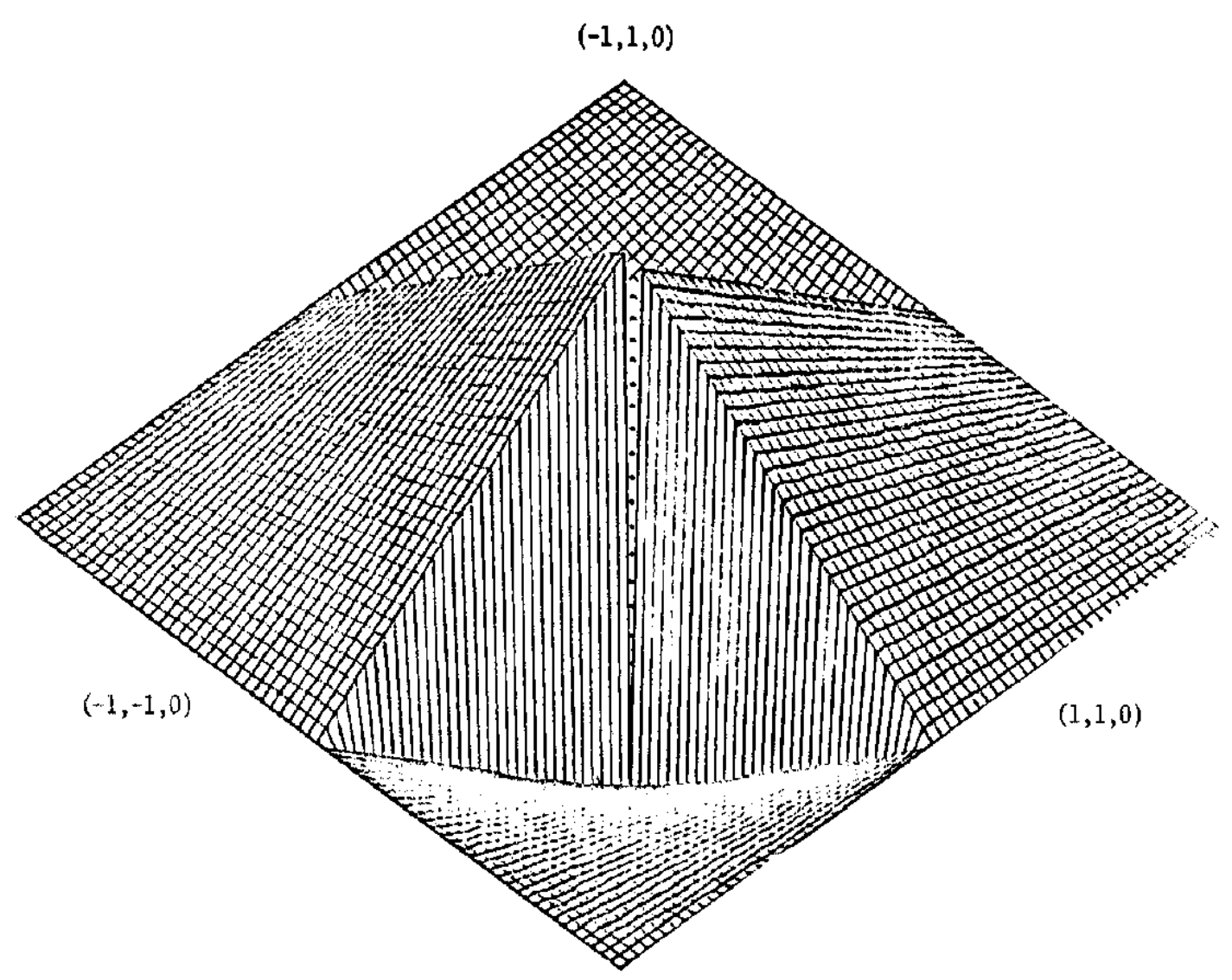

$(1,-1,0)$

Figure 2. 


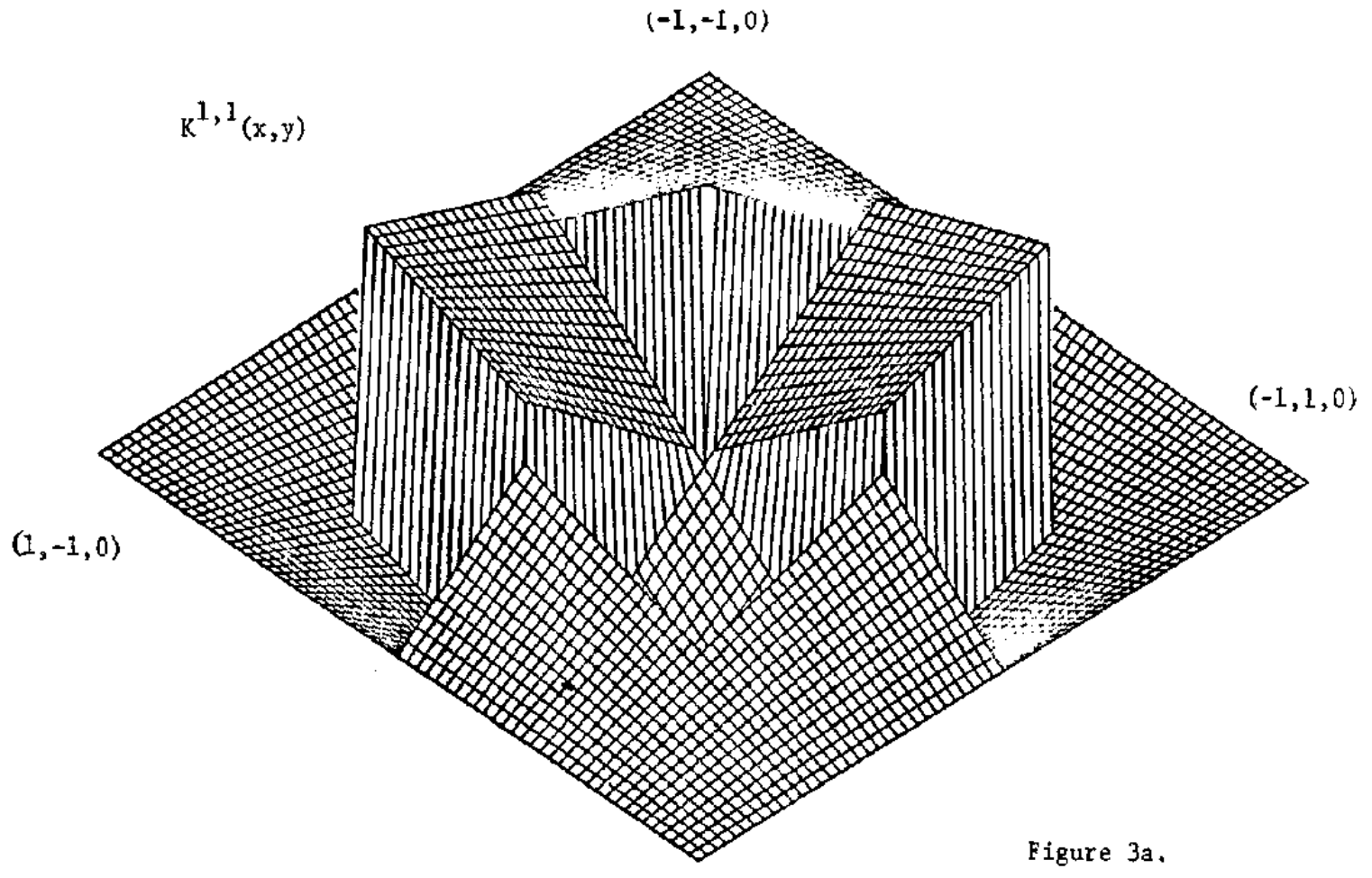

$(1,1,0)$

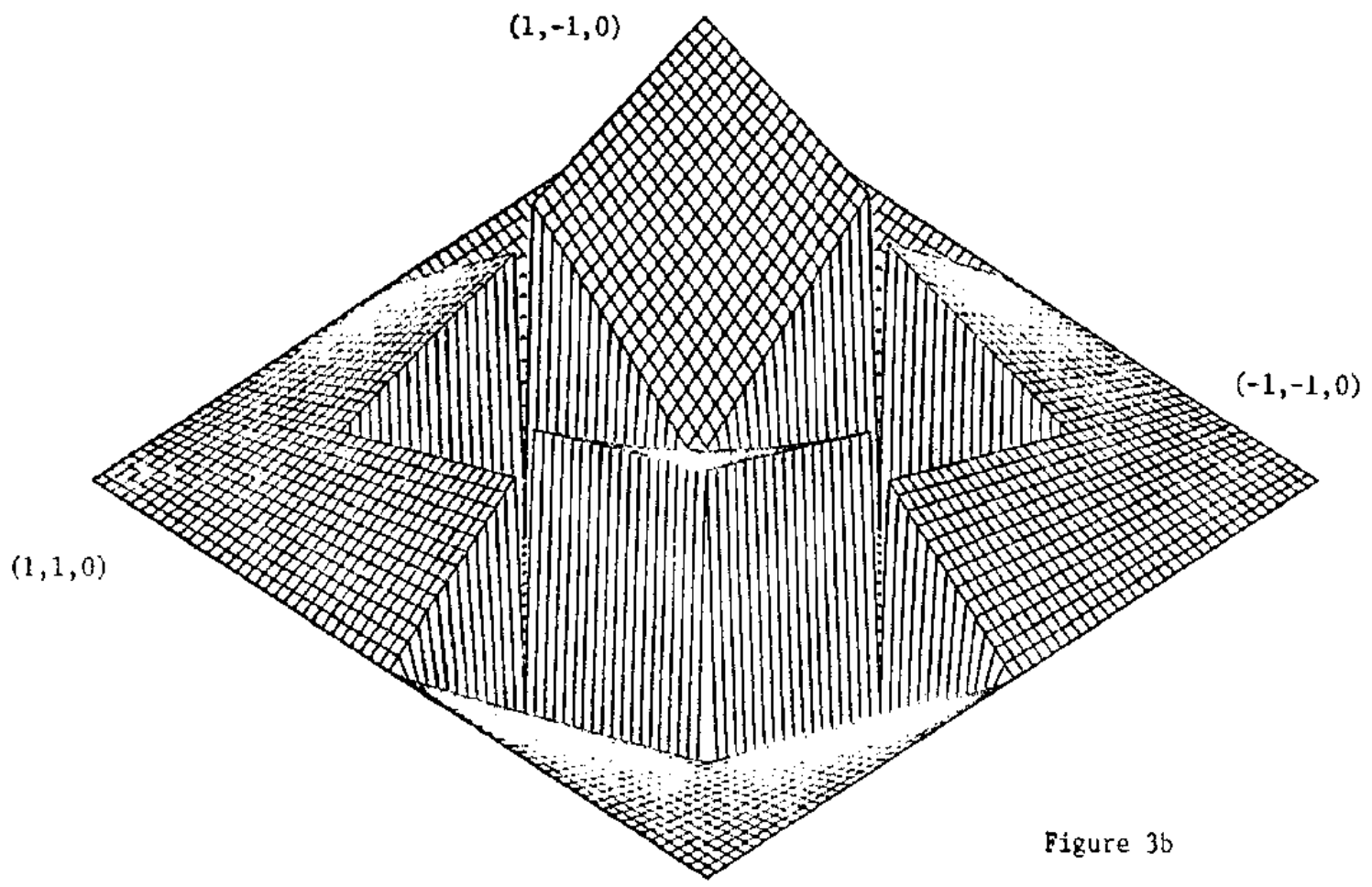

$(-1,1,0)$ 
Figures $3 \mathrm{a}$ and $3 \mathrm{~b}$ are two views of $\mathrm{K}^{1,1}(\mathrm{x}, \mathrm{y})$ for $\mathrm{G}_{2} \times \mathrm{G}_{2}$ with $(\alpha, \beta)=(0,0) \cdot$ Discontinuities like these along lines $x_{=}=x_{i}$ or

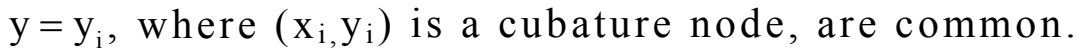

A proper choice of the parameters $\alpha$, and $\beta$ can result in continuous kernel functions, or, in some cases, continuous and positive. Figures 4,5 , and 6 show the effect of changing $(\alpha, \beta)$. The surface is $\mathrm{K}^{2,2}(\mathrm{x}, \mathrm{y})$ for $\mathrm{G}_{1} \times \mathrm{G}_{1}$.

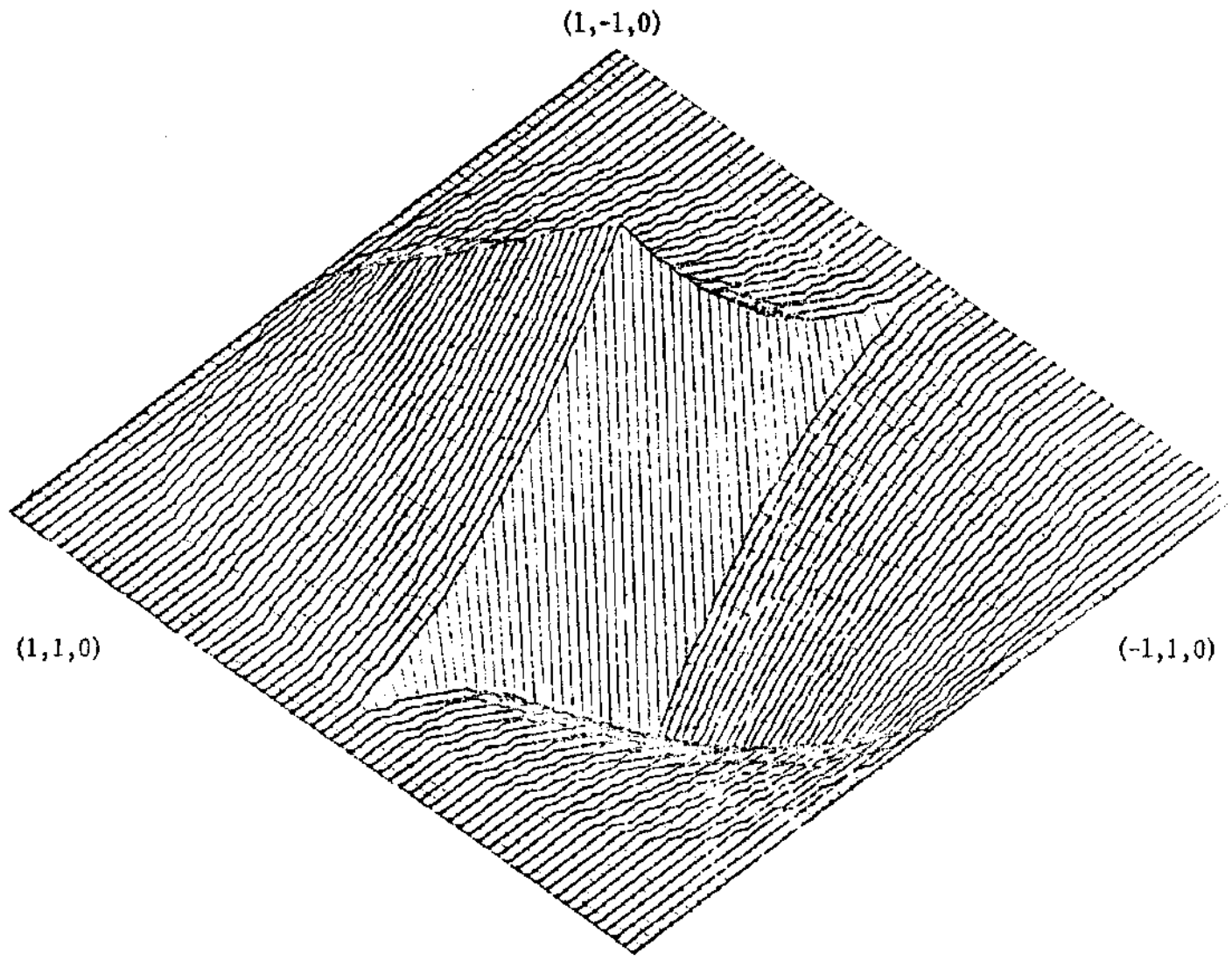

$(-1,1,0)$

Figure 4. 


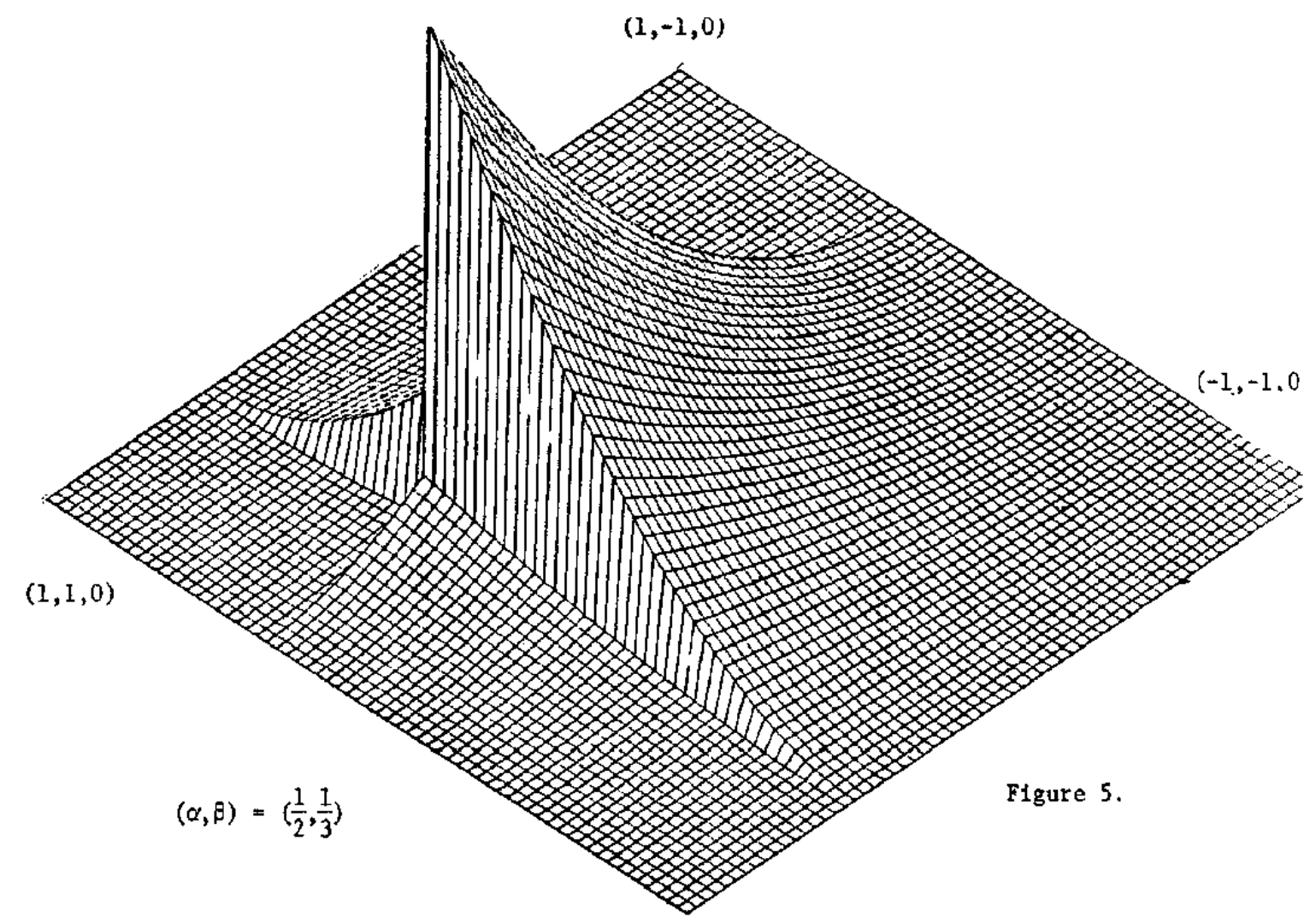

$(-1,1,0)$

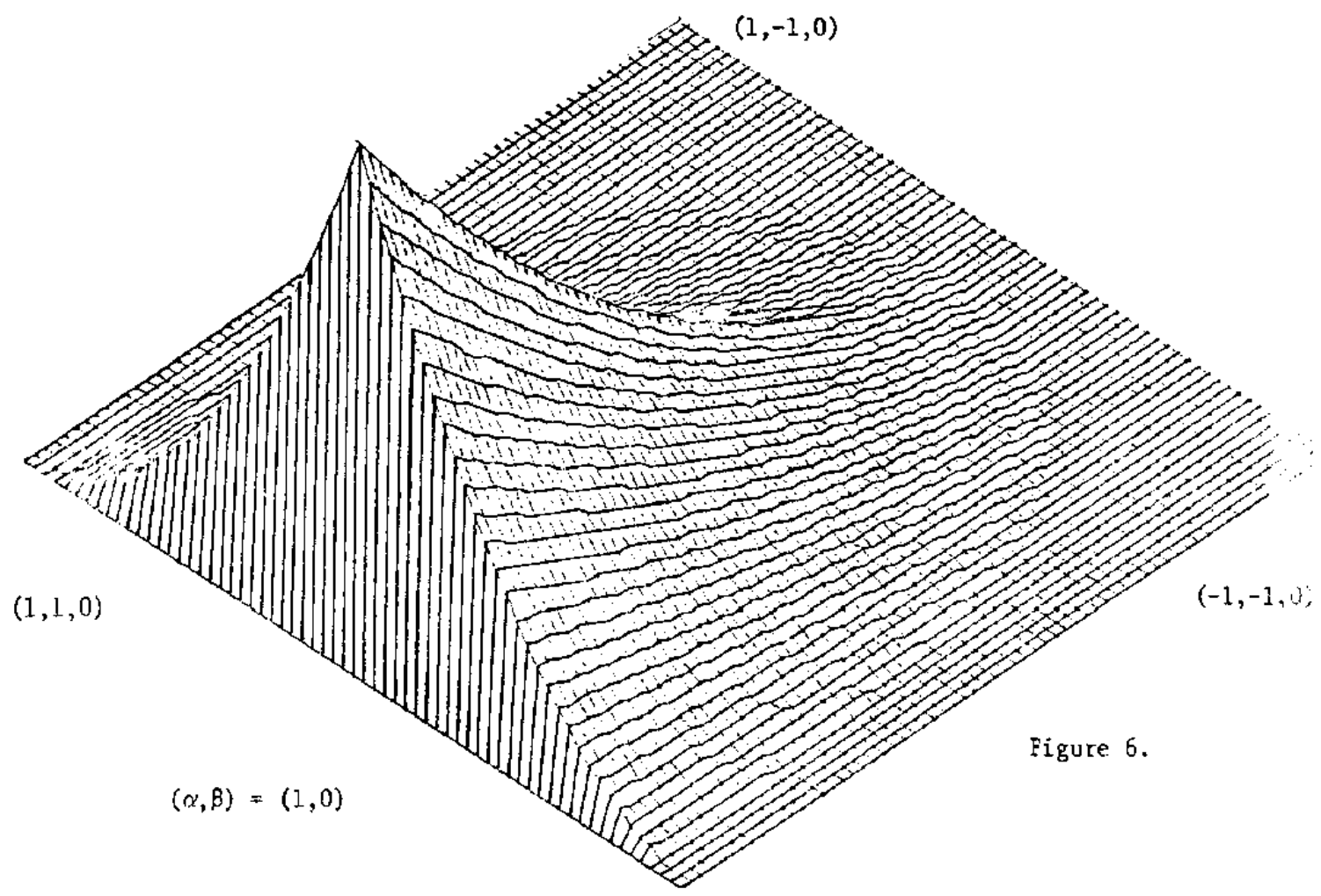

$(\cdots 1,1,0)$ 
Figure 7 shows a smooth positive surface for $k^{4,4}(x, y)$ for $\mathrm{G}_{2} \times \mathrm{G}_{2}$ with $(\alpha \beta)=(1,0)$.

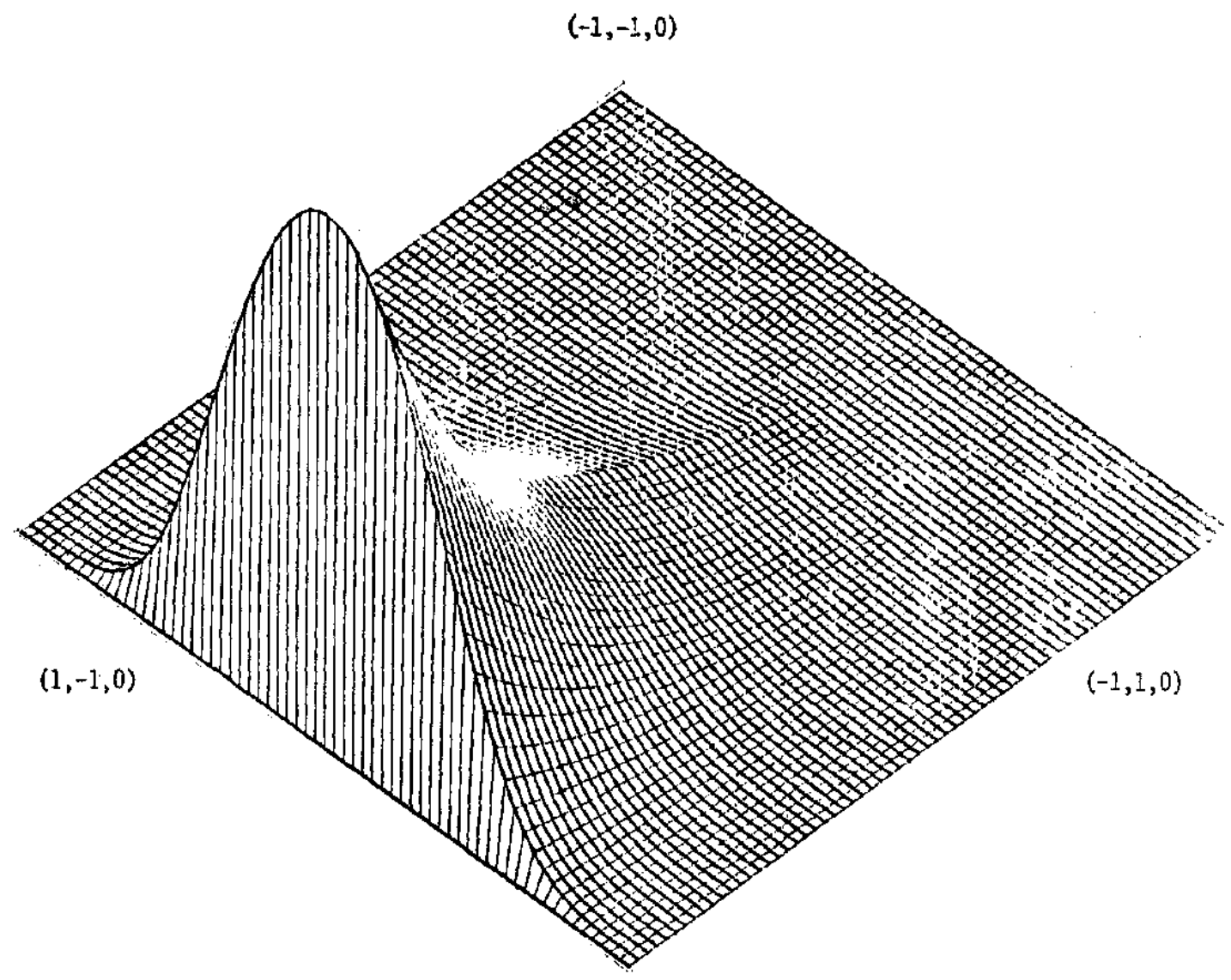

$(1,1,0)$

Figure 7.

Examples indicate that the $\mathrm{L}_{1}$ norm of the kernel grows excessively when the kernel is positive. 
The isometric views are drawn on a Gerber G22 plotter. The surface is approximated by drawing line segments connecting points on the surface occurring above a rectangular grid in the (x,y)-plane. Thus lines which should be seen as verticals appear often as "near" vertical. The program PSARD which produces the drawings is an extension of SARFUS [8] available at the University of Utah Computer Center. The flow of the program is the following: PSARD generates functional values at grid points on a square grid with step size $1 / 32$ over $[-1,1] \times[-1,1]-$ This step size was chosen since it gives a good picture of the surface without using too much computer time. The functional values are stored as a matrix. PSARD then calls SARFUS which edits the data; i.e., checks for errors and does horizontal and vertical scaling and rotation of the view, if desired. It calls ISOMET and several other subroutines which actually generate the driving program for the plotter. PSARD creates four views of the surface. Often all four views were needed to "see" the surface due to its discontinuities.

The following table gives $\mathrm{L}_{1}$ norms of one- and two-dimensional kernels for cross-product Legendre-Gauss rules. To simplify the calculations $\alpha$ and $\beta$ are chosen to be zero. The trapezoidal rule was used to compute the $\mathrm{L}_{1}$ norms of the two-dimensional kernels. 
TABLE 1

TABLE OF $\mathrm{L}_{1}$ NORMS OF KERNEL FUNCTIONS

\begin{tabular}{llcl} 
RULE & $\mathrm{p}, \mathrm{q}$ & $\left\|\mathrm{K}^{\mathrm{p}, 0}(\mathrm{x})\right\|=\left\|\mathrm{K}^{0, \mathrm{q}}(\mathrm{y})\right\|$ & $\left\|\mathrm{K}^{\mathrm{p}, \mathrm{q}}(\mathrm{x}, \mathrm{y})\right\|$ \\
\hline $\mathrm{G}_{3} \times \mathrm{G}_{3}$ & $\mathrm{p}=\mathrm{q}=1$ & .714 & .487 \\
& $\mathrm{p}=\mathrm{q}=3$ & $.109(-1)$ & $.870(-3)$ \\
& $\mathrm{p}=\mathrm{q}=6$ & $.171(-3)$ & $.464(-7)$ \\
$\mathrm{G}_{4} \times \mathrm{G}_{4}$ & $\mathrm{p}=\mathrm{q}=1$ & .555 & .425 \\
& $\mathrm{p}=\mathrm{q}=4$ & $.539(-3)$ & $.717(-5)$ \\
& $\mathrm{p}=\mathrm{q}=8$ & $.576(-6)$ & $.310(-11)$ \\
$\mathrm{G}_{5} \times \mathrm{G}_{5}$ & $\mathrm{p}=\mathrm{q}=1$ & .683 & .312 \\
& $\mathrm{p}=\mathrm{q}=5$ & $.159(-2)$ & $.531(-7)$ \\
& $\mathrm{p}=\mathrm{q}=10$ & $.298(-7)$ & $.807(-16)$
\end{tabular}

We use floating-point notation, i.e., $y(N)$ means $. y \times 10^{\mathrm{N}}$. 
The bivariate blending-function cubature rules [2] mentioned in the Introduction have the property that their remainders are formal products $\mathrm{R} \times \mathrm{S}$ of univariate remainders. That is $(\mathrm{R} \times \mathrm{S})(\mathrm{f})=$ $\iint_{I} f_{p, q}(x, y) k^{p, q}(x, y) d x d y$. if the quadratures are $Q_{R}$ and $Q_{S}$, respectively, then $\mathrm{Q}_{\mathrm{r}} \times \mathrm{Q}_{\mathrm{s}}$ is the cross-product rule with remainder $\mathrm{R} \oplus \mathrm{S}$ and $\mathrm{Q}_{\mathrm{R}} \oplus \mathrm{Q}_{\mathrm{s}}$ is the blending-function cubature with remainder $\mathrm{R} \times \mathrm{S}$,

\section{Computer Results for Efficient Cubatures and for Best Cubatures.}

For cubatures $\sum_{\mathrm{k}=1}^{\mathrm{n}} \mathrm{w}_{\mathrm{k}} \mathrm{f}\left(\mathrm{x}_{\mathrm{k}}, \mathrm{y}_{\mathrm{k}}\right)$ that are not cross-product rules, the more general Sard kernel theorem [5, p, 200] is used. For the integration functional $\int_{-1}^{1} \int_{-1}^{1}$, the following kernels are involved:

$$
\begin{aligned}
\mathrm{k}^{\mathrm{i}, \mathrm{j}}(\mathrm{x})= & \left\{(1-\beta)^{(\mathrm{j}+1)}-(-1-\beta)^{(\mathrm{j}+1)}\right\},\left\{\theta \theta(\mathrm{x} \alpha)(1-\mathrm{x})^{(\mathrm{i})}-[\theta \theta(\mathrm{x} \alpha)-1](-1-\mathrm{x})^{(\mathrm{i})}\right\} \\
& -\sum_{\mathrm{k}=1}^{\mathrm{n}} \mathrm{w}_{\mathrm{k}}\left(\mathrm{x}_{\mathrm{k}}-\mathrm{x}\right)^{(\mathrm{i}-1)}-\left(\alpha, \mathrm{x}, \mathrm{x}_{\mathrm{k}}\right)\left(\mathrm{y}_{\mathrm{k}}-\beta\right)^{(\mathrm{j})} \text { for }(\mathrm{i}, \mathrm{j}) \in \omega_{\mathrm{x}, \beta}
\end{aligned}
$$

$\mathrm{k}^{\mathrm{i}, \mathrm{j}}(\mathrm{y})$ is dual for $\bar{\omega}_{\alpha, \mathrm{y}}$;

$$
\begin{aligned}
\mathrm{k}^{\mathrm{p}, \mathrm{q}}(\mathrm{x}, \mathrm{y})= & {[\theta(\mathrm{x}, \alpha)-1][\theta(\mathrm{y}, \beta)-1](-1-\mathrm{x})^{(\mathrm{P})}(-1-\mathrm{y})^{(\mathrm{q})} } \\
& -1[\theta(\mathrm{x}, \alpha)-1] \theta(\mathrm{y}, \beta)(-1-\mathrm{x})^{(\mathrm{P})}(1-\mathrm{y})^{(\mathrm{q})} \\
& -\theta(\mathrm{x}, \alpha) \theta(\mathrm{y}, \beta)-1](-1-\mathrm{x})^{(\mathrm{p})}(1-\mathrm{y})^{(\mathrm{q})} \\
& +\theta(\mathrm{x}, \alpha) \theta(\mathrm{y}, \beta)-1](-1-\mathrm{x})^{(\mathrm{p})}(-1-\mathrm{y})^{(\mathrm{q})} \\
& -\sum_{\mathrm{k}=1}^{\mathrm{n}} \mathrm{w}_{\mathrm{k}}\left(\mathrm{x}_{\mathrm{k}}-\mathrm{x}\right)^{(\mathrm{p}-1)} \psi\left(\alpha, \mathrm{x}, \mathrm{x}_{\mathrm{k}}\right)\left(\mathrm{y}_{\mathrm{k}}-\mathrm{y}\right)^{(\mathrm{q}-1)} \psi\left(\beta, \mathrm{y}, \mathrm{y}_{\mathrm{k}}\right),
\end{aligned}
$$


where $\psi\left(\alpha, \mathrm{x}, \mathrm{x}_{\mathrm{k}}\right)=\theta(\mathrm{x}, \alpha)-\theta\left(\mathrm{x}, \mathrm{x}_{\mathrm{k}}\right)$ and $\bar{\omega}_{\mathrm{x}, \beta}$ and $\bar{\omega}_{\alpha, \mathrm{y}}$ are certain index sets defined in Sard. By use of the triangle inequality, the following rough estimate can be obtained.

$$
\frac{\left\|\mathrm{K}^{\mathrm{i}, \mathrm{j}}\right\| \mathrm{L}_{1}}{\left\|\mathrm{~K}^{\mathrm{p}, \mathrm{q}}\right\| \mathrm{L}_{1}} \approx \frac{\mathrm{p} ! \mathrm{q} !}{\mathrm{i} !(\mathrm{j}+1) !}
$$

Let $(\alpha, \beta)=(0,0)$ and $\mathrm{R}(\mathrm{f}) \equiv \int_{-1}^{1} \int_{-1}^{1} \mathrm{f}-\sum_{\mathrm{k}=1}^{\mathrm{n}} \mathrm{w}_{\mathrm{k}} \mathrm{f}\left(\mathrm{x}_{\mathrm{k}}, \mathrm{y}_{\mathrm{k}}\right)$.

If appropriate precision is assumed, then the preceding kernels can be used to obtain the following theorem:

$$
\begin{aligned}
|R(f)| \leqq & \sum_{(i, j) \in \bar{\omega}_{x, 0}}\left\|f_{i, j}(x, 0)\right\|_{L^{\infty}}\left\|K^{i, j}(x)\right\|_{L_{1}} \\
& +\sum_{(i, j) \in \bar{\omega}, y}\left\|f_{i, j}(0, y)\right\|_{L^{\infty}}\left\|K^{i, j}(y)\right\|_{L_{1}} \\
& +\left\|f_{p, q}(x, y)\right\|_{L^{\infty}}\left\|K^{p, q}(x, y)\right\|_{L_{1}}
\end{aligned}
$$

We apply (2) to a 14-point precision seven formula due to Franke [3]. An efficient cubature is a cubature in which the weights and nodes are chosen so as to integrate exactly a maximal number of the lowest order monomials. Franke's cubatures are constructed so as to be more efficient than known cubatures with the same number of nodes. If $f_{i, j}$ is continuous for $\mathrm{i}$ and $\mathrm{j}$ such that $\mathrm{i}+\mathrm{j}=6, \mathrm{p}=\mathrm{q}=3$, then $|R(f)| \leqq .152(-2) \max _{\substack{i+j=6 \\ \text { and }}}\left|f_{i, j}(x, y)\right|$, where bounds on the $L_{1}$, norms of the seven kernels required are given in the first part of Table 2 . 
The weights and nodes of the cubature formula

$$
\int_{-1}^{1} \int_{-1}^{1} f(x, y) d x d y=\sum_{n=1}^{14} w_{i} f\left(x_{i} y_{i}\right)+R(f)
$$

are given below,

$$
\begin{array}{lcc}
\multicolumn{1}{c}{\mathrm{x}_{\mathrm{i}}} & \mathrm{y}_{\mathrm{i}} & \multicolumn{1}{c}{\mathrm{W}_{\mathrm{i}}} \\
\pm .774596669241483 & \pm \mathrm{r} & .193252691743630 \\
.0 & \pm \mathrm{r} & .309204306788848 \\
\pm .915060523380880 & \pm \mathrm{S} & .1690499212109002 \\
\pm .396191039748320 & \pm \mathrm{S} & .483095233643544 \\
& \mathrm{r}=.861136311594053 \\
& \mathrm{~s}=.339981043584856
\end{array}
$$

Figure 8 depicts $\mathrm{K}^{3,3}$ multiplied by $10^{3}$.

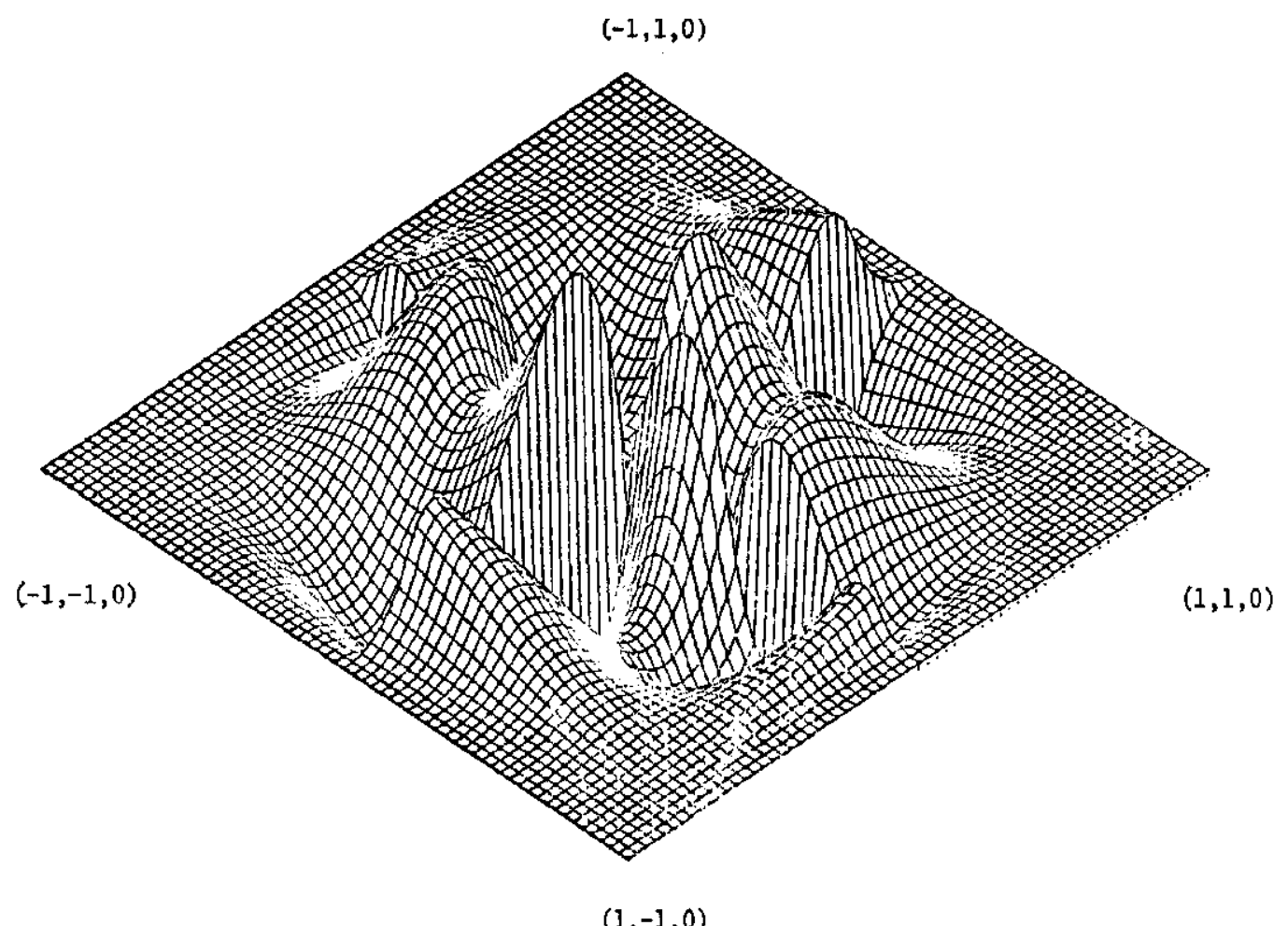

$(1,-1,0)$

Figure3 
A second 14-point precision seven formula with nodes outside the square by Franke is given below. Bounds for the kernels are given in the second part of Table 2 .

$$
\begin{aligned}
& \begin{array}{ccc}
\mathrm{X}_{\mathrm{i}} & \mathrm{y}_{\mathrm{i}} & \mathrm{W}_{\mathrm{i}} \\
\pm 1.05784012371275 & \pm \mathrm{r} & .0437841520872291
\end{array} \\
& \pm .774596669241483 \quad \pm_{\mathrm{S}} \quad .362302863812526 \\
& \begin{array}{lll}
.0 & \pm \mathrm{s} & .579684582100041
\end{array} \\
& \pm .469253522127911 \quad \pm \mathrm{r} \quad .304070693050225 \\
& \mathrm{r}=.861136311594053 \\
& \mathrm{~s}=.339981043584856
\end{aligned}
$$

We apply (2) to a 7-point minimum norm cubature due to Barnhill and Nielson [1, Table 1, $\rho=\infty$ ]. Minimum norm cubatures are cubatures that minimize the norm of the remainder functional in an appropriate Hilbert space. These cubatures are not efficient in that they need not integrate low order monomials exactly. Thus these rules are a kind of opposite to Franke's rules. The minimum norm cubatures do integrate exactly the representers of the point functionals corresponding to the cubature's nodes. If $\mathrm{f} \in \mathrm{B}_{4,4}$, then

$$
|R(f)| \leqq .464(-3) \quad \max _{i+j=8}\left|f_{i, j}(x, y)\right|
$$

where bounds on the $\mathrm{L}_{1}$ norms of the seven kernels required are given in the first part of Table 3 . 
Figure 9 depicts $\mathrm{K}^{4,4}$ multiplied by $10^{3}$.

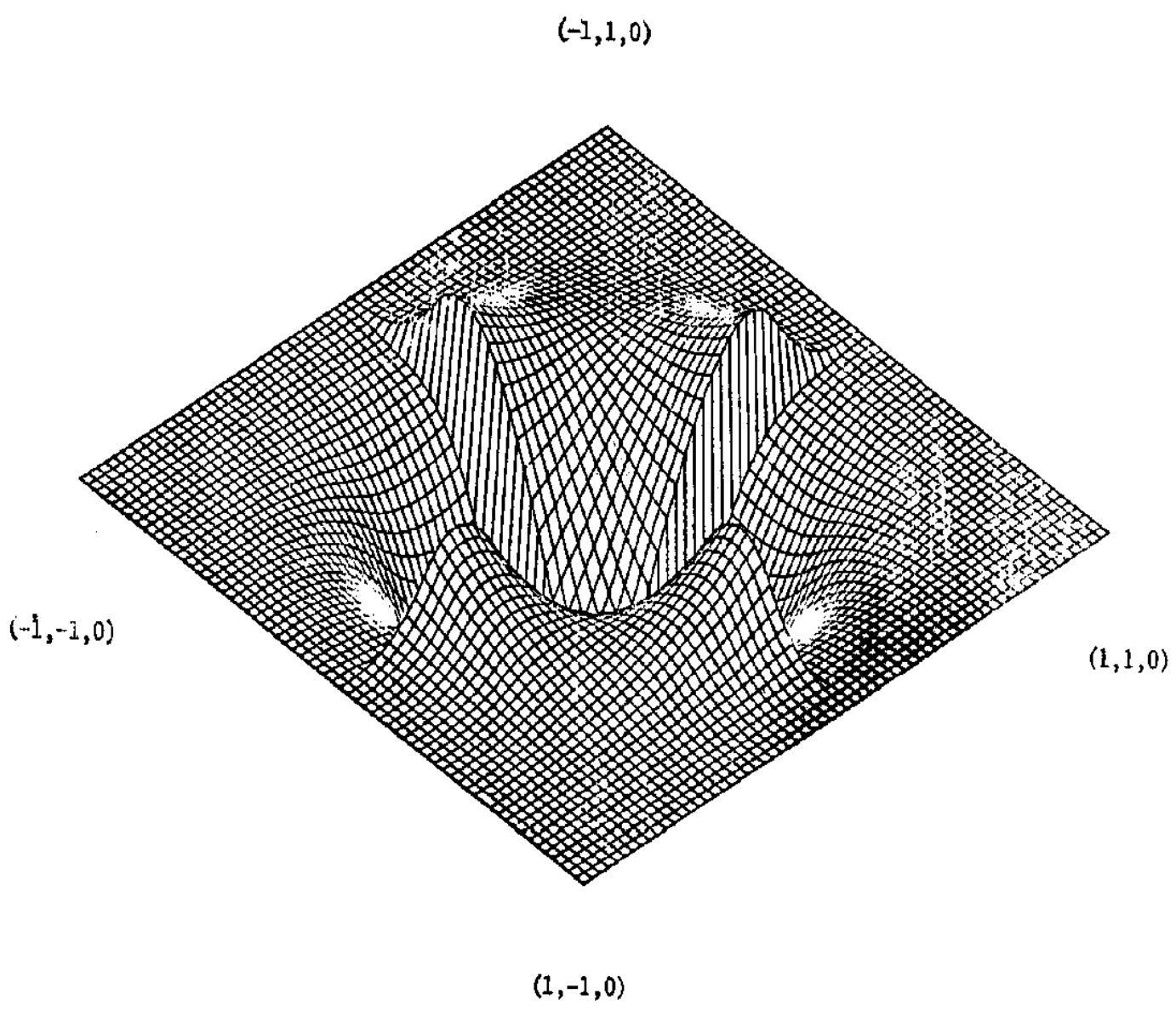

Figure 9 
TABLE 2

14-POINT RULE WITH PRECISION 7, by Franke.

\begin{tabular}{lcl}
$\mathrm{p}, \mathrm{q}$ & Bound for 1 dimensional kernels & $\| \mathrm{K}^{\mathrm{p}, \mathrm{q}}(\mathrm{x}, \mathrm{y} \|$ \\
\hline $\mathrm{p}=\mathrm{q}=1$ & $.437(-1)$ & .510 \\
$\mathrm{P}=\mathrm{q}=3$ & $.189(-3)$ & $.382(-3)$
\end{tabular}

14-FOINT RULE WITH PRECISION 7 (WITH NODES OUTSIDE THE SQUARE), by Franke

\begin{tabular}{lcl}
$\mathrm{p}, \mathrm{q}$ & Bound for 1 dimensional kernels & $\| \mathrm{K}^{\mathrm{p}, \mathrm{q}}(\mathrm{x}, \mathrm{y} \|$ \\
\hline $\mathrm{p}=\mathrm{q}=1$ & $.437(-1)$ & .499 \\
$\mathrm{p}=\mathrm{q}=3$ & $.305(-3)$ & $.630(-3)$
\end{tabular}

TABLE 3

7-POINT RULE, by Barnhill and Nielson [1, Table 1, $\rho=\infty]$.

\begin{tabular}{lcll}
$\mathrm{p}, \mathrm{q}$ & Bound for 1 dimensional kernels & $\| \mathrm{K}^{\mathrm{p}, \mathrm{q}}(\mathrm{x}, \mathrm{y} \|$ & Bound for $\mathrm{c}^{\mathrm{i}, \mathrm{j}}$ \\
\hline $\mathrm{p}=\mathrm{q}=1$ & $.263(-1)$ & .505 & $.340(-5)$ \\
$\mathrm{p}=\mathrm{q}=3$ & $.123(-2)$ & $.244(-2)$ & $.340(-5)$
\end{tabular}

7-POINT RULE, by Barnhlll and Nielson [1, Table 2, $\rho=\infty]$.

\begin{tabular}{lcll}
$\mathrm{p}, \mathrm{q}$ & Bound for 1 dimensional kernels & $\| \mathrm{K}^{\mathrm{p}, \mathrm{q}}(\mathrm{x}, \mathrm{y} \|$ & \multicolumn{1}{c}{ Bound for $\mathrm{c}^{\mathrm{i}, \mathrm{j}}$} \\
\hline $\mathrm{P}=\mathrm{q}=1$ & $.749(-1)$ & .560 & $.247(-2)$ \\
$\mathrm{p}=\mathrm{q}=3$ & $.303(-3)$ & $.156(-2)$ & $.247(-2)$
\end{tabular}




\section{REFERENCES}

1. Barnhill, R, E. and Nielson, G. M., An Error Analysis for Numerical Multiple Integration III., Math, of Comp., April, 1970, Vol. 24, No, 110, pp. 301-314.

2. Barnhill, R. E., Gordon, W. J., and Thomas, D. H., The Method of Successive Decomposition for Multivariate Integration, General Motors Research Laboratories, Warren, Michigan, GMR report.

3. Franke, R. H., Orthogonal Polynomials and Approximate Multiple Integration, Ph.D. thesis, Dept. of Math., U. of Utah, Salt Lake City, Utah (1970).

4. Lether, F. G., Cross-Product Cubature Error Estimates, Ph.D. thesis, Dept. of Math., U. of Utah, Salt Lake City, Utah (1969).

5. Sard, A., Linear Approximation, Math. Surveys, No. 9, Amer. Math. Soc., Providence, R. I. (1963). MR 28\#1429.

6. Stroud, A. K., Approximate Calculation of Multiple Integrals, Prentice-Hall, Englewood Cliffs, N. J. (1971).

7. Stroud, A. H. and Secrest, D., Gaussian Quadrature Formulas, Prentice-Hall, Englewood Cliffs, N. J. (1966). 